\title{
Endoskopik transpapiller safra kesesi drenajı: Tek merkez deneyimi
}

\section{Endoscopic transpapillary gallbladder drainage: Single center experience}

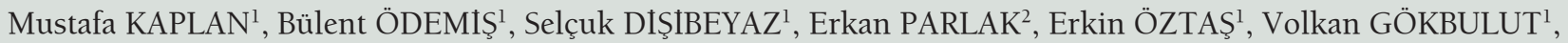
Orhan COŞKUN ${ }^{1}$

Türkiye Yüksek Ihtisas Eğitim ve Araștırma Hastanesi, ${ }^{1}$ Gastroenteroloji Kliniği, Ankara

Hacettepe Universitesi Tip Fakültesi, ${ }^{2}$ Gastroenteroloji Bilim Dal, Ankara

Giriş ve Amaç: Bu çalışmada komorbit durumlarnn eşlik ettiği sistik kanal veya safra kesesi ilişkili hastalıklarda ERCP ile transpapiller safra kesesi drenajının teknik ve klinik başarısını ve komplikasyonlarını araştırdık. Gereç ve Yöntem: Bu çalışma 2011-2017 yılları arasında koledok taşı, kolanjit veya Mirizzi sendromu nedeniyle endoskopik retrograd kolanjiopankreotografi endikasyonu zaten konulan ve eşlik eden akut kolesistiti olan toplam 19 hasta ile yapıldı. Endikasyona göre koledok taşları ve sistik kanal taşları çıkarıldıktan veya koledoğa stent yerleştirildikten sonra tüm hastalarda nazosistik dren veya pigtail stent ile transpapiller safra kesesi drenajı sağland. Transpapiller safra kesesi drenajının teknik ve klinik başarısı ve işlemin komplikasyonları değerlendirildi. Bulgular: Hastaların 15'inde (\%79) en az bir komorbid hastalık vardı. 10 hastada sistik kanalda taş izlendi. Sistik kanalında tas olan tüm hastalara balon ile lavaj, 3 hastaya basket ve mekanik litotripsi ve bir hastaya da sistik kanal girişine balon dilatasyonu uyguland. Transpapiller safra kesesi drenaj1 8 hastada $7 F$ nazosistik dren, 6 hastada $7 F$ nazobiliyer drenden yapılma stent, 3 hastada $7 F$ double pigtail stent ve 2 hastada $10 F$ double pigtail stent ile sağlandı. Çalışmada transpapiller safra kesesi drenajının teknik başarısı \%100 ve klinik başarısı \%89 olarak bulundu. Işleme bağlı ölüm dahil herhangi bir komplikasyon görülmedi. Sonuç: Komorbit durumların eşlik ettiği safra kesesi veya sistik kanal ile ilişkili hastalıklarda endoskopik retrograd kolanjiopankreotografi ile transpapiller safra kesesi drenajı başarılı ve komplikasyonu az bir yöntemdir.

Anahtar kelimeler: Akut kolesistit, safra kesesi drenajı, endoskopik retrograd kolanjiopankreotografi

\section{GİRİs}

Endoskopik retrograd kolanjiopankreotografi (ERCP) pankreatobiliyer hastalıkların tanı ve tedavisinde sıklıkla kullanılan girişimsel bir yöntemdir (1). En sık kullanım endikasyonları ise koledok taşı, kolanjit, malign ve benign biliyer darlıklar gibi biliyer obstrüksiyon durumları, biliyer ve pankreatik kaçaklar ve pankreatik kanal ilişkili hastalıklardır (24). Mirizzi sendromu gibi safra kesesi ilişkili hastalıklarda ise yine biliyer obstrüksiyonun üstesinden gelmek için sıklıkla ERCP gerekmektedir (5). Ancak komorbit durumları olup, acil kolesistektomi yapilamayacak akut kolesistit tanılı hastalarda ERCP ile safra kesesinin drenajı yeni uygulanan ve literatürde hakkında çok fazla çalışma olmayan bir klinik durumdur (6). Widmer ve ark. yaptığı çalışmada akut kolesistit tanısı ile başvuran ve komorbit durumlar nedeniyle kolesistektomi yapılamayan hastalarda ERCP ile sistik kanal üzerinden keseye stent konulmasının başarılı ve komplikasyonu az
Background and Aims: In this study, we investigated the technical and clinical success and complications of transpapillary gallbladder drainage with endoscopic retrograde cholangiopancreatography in patients with gallbladder or cystic duct related diseases accompanied by comorbid conditions. Material and Methods: This study was performed on 19 patients with acute cholecystitis who had already an indication for endoscopic retrograde cholangiopancreatography due to choledocholitiasis, cholangitis or Mirizzi syndrome between 2011-2017. After choledochal and cystic duct stones had been removed, or choledochal stents had been placed according to indication, transpapillary gallbladder drainage with nasocystic drain or pigtail stent were provided in all patients. The technical and clinical success of transpapillary gallbladder drainage and the complications of the procedure were evaluated. Results: 15 (79\%) of the patients had at least one comorbid disease. Cystic duct stones were observed in 10 patients. Balloon lavage to all patients with cystic duct stones, basket and mechanical lithotripsy to 3 patients, and balon dilatation to the entrance of cystic duct to one patient were applied. Transpapillary gallbladder drainage was provided with $7 F$ nasocystic drain in 8 patients, stent made from $7 F$ nasobiliary drain in 6 patients, $7 F$ double pigtail stent in 3 patients and IOF double pigtail stent in 2 patients. In this study, the technical success of transpapillary gallbladder drainage was found $100 \%$ and clinical success was found $89 \%$. No complications including death were observed due to the procedure. Conclusion: Transpapillary gallbladder drainage with endoscopic retrograde cholangiopancreatography is a successful and less complicated procedure in patients who have gallbladder or cystic duct related diseases with comorbid conditions.

Key words: Acute cholecystitis, gallbladder drainage, endoscopic retrograde cholangiopancreatography

olan bir işlem olduğunu göstermiştir (7). Biz de bu çalışmada 3. basamak bir merkezde ERCP ile transpapiller safra kesesi drenajının endikasyonlarını, teknik ve klinik başarısını ve komplikasyonlarını araştırdık.

\section{GEREC ve YÖNTEM}

Bu çalışma 2011-2017 yılları arasında Türkiye Yüksek Ihtisas Eğitim ve Araştırma Hastanesi Gastroenteroloji Kliniğinde ERCP yapılan hastaların hasta kayıtları incelenerek yapılmıştır. Çalışmaya koledok taşı, kolanjit, Mirizzi sendromu nedeni ile ERCP endikasyonu konulan ve eşlik eden akut kolesistit tablosu olan hastalar dahil edilmiştir. Toplamda 10.000 ERCP kaydı incelenmiş ve 30 hasta bu kriterleri doldurduğu için çalışmaya alınmıştır. 11 hasta veri eksikliği ve dışlanma kriterleri nedeniyle çalışmadan dışlanmıştır. Çalışmaya 19 hasta dahil edilmiștir.
İletişim: Mustafa KAPLAN, Türkiye Yüksek İhtisas Eğitim ve Araştırma Hastanesi, Gastroenteroloji, Kızılay Caddesi, 06100, Sıhhiye, Ankara Fax: +90 31231241 20•E-mail: mustafakaplandr@yahoo.com Geliş Tarihi: 10.07.2018 Kabul Tarihi: 19.10.2018 
ERCP yapılan hastaların biliyer endikasyonları dosyalarından kaydedilmiştir. Safra kesesi boynu veya sistik kanala yerleşen bir taşın koledoğa yandan bası yapması sonucu tıkanma sarılığı gelişen hastalar Mirizzi sendromu olarak alınmıştır.

Komorbit durumlar 6 ana başlık altında toplanmıştır: Malign hastalıklar, ciddi kardiyovasküler hastalıklar, ciddi solunumsal hastalıklar, hematolojik hastalıklar [uluslararası normalleştirilmiş oran (INR) > 1.5 veya trombosit $<50.000$ ] ve septik kolanjit. Ortalama takip süresi olarak; stent değişimi, kolesistektomi veya ölüme kadar geçen süre alınmıştır. Çalışma öncesi kolesistit tablosu için perkütan kolesistostomi yapılan ve tanı anında safra kesesi perforasyonu olan hastalar çalışmadan dışlanmıştır.

Teknik başarı sistik kanal üzerinden safra kesesine başarılı bir şekilde drenaj kateteri konulması olarak tanımlanmıştır. Klinik başarı ise akut kolesistit endikasyonu ile yapılan hastalarda kolesistit tablosunun klinik, laboratuvar ve radyolojik olarak düzelmesi olarak tanımlanmıştır.

Komplikasyonlar mevcut ERCP kılavuzları (8) göz önüne alınarak 5 ana grupta toplanmıştır: ERCP ilişkili pankreatit, endoskopik sfinkterotomiye (EST) bağlı kanama, perforasyon, stent migrasyonu ve stent oklüzyonu. Issleme bağlı mortalitenin değerlendirilmesi için işlem tarihinden itibaren 30 günlük sürede gerçekleşen mortalite esas alınmıştır. Total mortalite oranı ise takip süresince mortalite gelişen hastaların dosyaları ölüm bildirim sisteminden taranarak elde edilmiştir.

Tüm ERCP işlemleri midozolam ve petidin altında anestezi ile deneyimli iki endoskopist tarafından yapıldı. ERCP kanülasyonu için selektif ve pre-cut olmak üzere iki yöntem alınd. Pankreas kanalına mükerrer tel gidişi durumunda pankreas kanalına pankreatik stent konuldu. Biliyer obstrüksiyonu olan hastalarda koledoğa işlem veya gerekirse stentleme yapıldı. Koledok ve sistik kanal görüntülenmesi için balon oklüde kolanjiyogram alındı. Sistik kanal tüm hastalarda tel üzerinden standart kanülize edildi. Standart olarak kanülizasyon için 0.035 inch Visiglide (Olympus Corp., Center Valley, PA,USA) kullanıldı ve tel safra kesesi içinde dolandırıldı. İhtiyaç duyulduğunda sistik kanal girişi balon ile dilate edildi. Sistik kanalda taş olan hastalara ihtiyaç durumuna göre balon ile lavaj, basket veya mekanik litotripsi ile taş kırma işlemi uygulandı. Tüm hastalara klinik ve skopik görüntü esas alınarak 4 çeşit drenaj yöntemi kullanıldı: Nazosistik dren, 7F nazobiliyer dren (NBD)'den yapilma stent, 7F ve $10 \mathrm{~F}$ double pigtail stentler.

\section{BULGULAR}

Araştırmaya 11 kadın (\%58) ve 8 erkek (\%42) olmak üzere 19 hasta katıldı. Hastaların ortalama yaşı 63'tü. Hastaların \%79'unda en az bir komorbid hastalık vardı. En sık görülen komorbid durumlar ise septik kolanjit, ciddi kardiyovasküler ve solunumsal hastalıklar, karaciğer yetmezliği ve hematolojik bozukluklardı. Hastaların ortalama takip süresi 80 gündü. 15 (\%79) hastaya yatış verilerek işlem yapılırken bu 15 hastadan sadece 4'ünün yoğun bakım ihtiyacı oldu. Ortalama ERCP seans sayısı 1.9 olarak bulundu. Hastaların ERCP bulguları incelendiğinde 6 hastanın (\%32) daha önce endoskopik sfinkterotomi (EST)'li olduğu, 12 hastaya (\%63) ilk defa EST yapıldı̆̆ı, 1 hastaya (\%5) ise INR yüksek olduğu için EST yapılmadığı görüldü. 3 hastada (\%16) divertikül mevcuttu. 15 hastada koledok selektif (\%79), 4 hastada ise precut yöntemi ile (\%21) kanülize edildi. 10 hastada (\%53) eşlik eden kolanjit ve 5 hastada (\%26) koledok taşı tespit edilmiş olup toplam 14 hastada (\%74) koledoğa stent takıldı. ERCP işleminin en sık biliyer endikasyonları ise Mirizzi sendromu ve kolanjitti. Çalışmaya ait demografik özellikler Tablol'de özetlenmiştir.

\section{Tablo 1. Demografik özellikler}

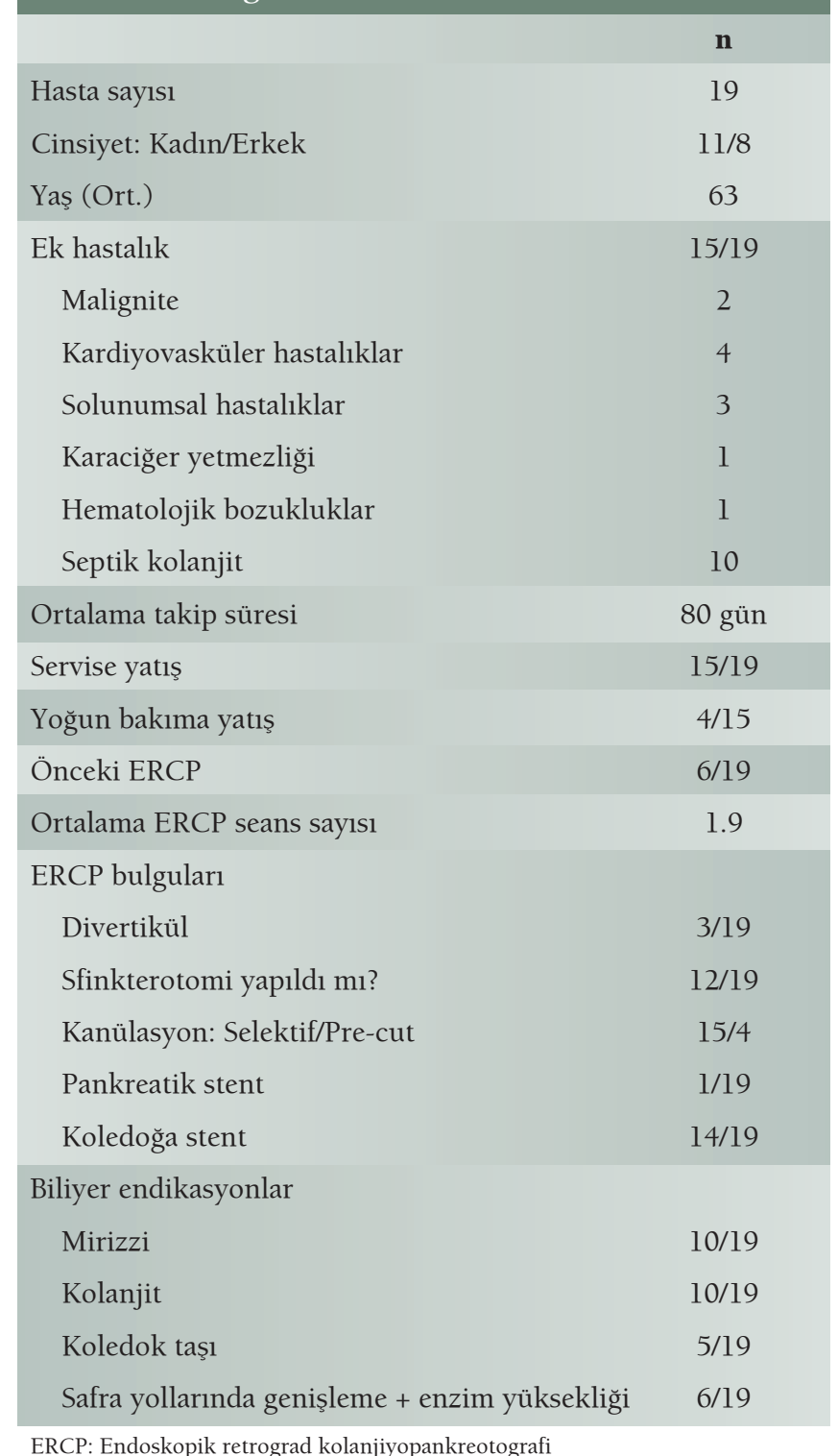


Sistik kanal inceleme bulguları Tablo 2'de verilmiştir. Çalışmadal0 hasta (\%53) sistik kanalda taş görülerek Mirizzi sendromu tanısı aldı. Bu hastalardan iki tanesinde tip 2 Mirizzi, 8 hastada tip 1 Mirizzi sendromu saptandı. Sistik kanalda taş görülen tüm hastalara balon ile lavaj, 3 hastaya lavaj ile beraber basket ve mekanik litotripsi ve 1 hastaya da sistik kanal girişine balon dilatasyonu uygulandı. Sistik kanalı kanülize edilen çalışmadaki tüm hastalara drenaj için stent veya nazosistik dren konuldu. Drenaj için en sık kullanılan yöntemler ise nazosistik dren (\%42) ve NBD'den yapılma stentlerdi (\%31).

Çalışmanın sonlanım noktaları Tablo 3'te verilmiştir. Çalışmada teknik başarı \%100 bulunurken klinik başarı \%89 ola-

\begin{tabular}{|cc}
\hline Tablo 2. Sistik kanal işlem bulguları & \\
\hline Dilate sistik kanal & n \\
Sistik kanalda taş (Mirizzi Sendromu) & $10 / 19$ \\
Tip 1 & $10 / 19$ \\
Tip 2 & $8 / 10$ \\
Sistik kanala balon ile lavaj & $2 / 10$ \\
Sistik kanala basket & $10 / 19$ \\
Sistik kanala balon dilatasyonu & $3 / 19$ \\
Safra kesesi drenajı & $1 / 19$ \\
Nazosistik dren & $19 / 19$ \\
7F NBD'den yapılma stent & 8 \\
7F DP & 6 \\
10F DP & 3 \\
\hline NBD. Nazobiliyer dren, DP. Double pigtail & 2
\end{tabular}

Tablo 3. İşlem sonlanım noktaları

\begin{tabular}{lc} 
& n \\
\hline Teknik başarı & $19 / 19$ \\
\hline Klinik başarı & $17 / 19$ \\
\hline Perkütan kolesistostomi & $2 / 19$ \\
\hline Kolesistektomi & $5 / 19$ \\
\hline İsleme bağlı mortalite & $0 / 19$ \\
\hline Total mortalite & $5 / 19$ \\
Komplikasyonlar & $0 / 19$ \\
\multicolumn{1}{|c|}{ Pankreatit } & $0 / 19$ \\
EST kanama & $0 / 19$ \\
Perforasyon & $0 / 19$ \\
Stent migrasyonu & $0 / 19$ \\
Stent oklüzyonu & $0 / 19$
\end{tabular}

EST: Endoskopik sfinkterotomi. rak bulundu. İki hastada (\%11) klinik başarı sağlanamadığı için hastalara perkütan kolesistostomi yapıldı. Işleme bağlı ölüm dahil herhangi bir komplikasyon görülmezken takip süresince toplam 5 hastada (\%26) mortalite gelişti.

\section{TARTIŞMA}

Bu çalışmada komorbit durumları olan hastalarda ERCP ile transpapiller safra kesesi drenajının başarılı ve komplikasyonu az bir işlem olduğu gösterilmiştir. Çalışmada ERCP ile safra kesesine stent veya nazosistik dren konulması işleminin teknik başarısı \%100, klinik başarısı ise \%89 bulunmuş ve işleme bağlı hiçbir komplikasyon görülmemiştir.

Çalışmamızda en sık komorbid durumlar septik kolanjit, ciddi kardiyovasküler ve solunumsal hastalıklar olarak bulunmuştur. Daha önce Widmer ve ark.'nın yaptığı çalışmada da benzer komorbid durumlar bulunmuştur (7). Ancak bizim çalışmamızda Widmer ve ark.'nın çalışmasına göre karaciğer yetmezliği ve malignite tanısı olan hastaların oranı düşük iken septik kolanjiti olan hastaların oranı ise daha yüksek bulunmuştur. Bunun nedeni ise merkezimizin kolanjit tanılı hastalar için bir sevk merkezi olması olabilir.

Çalışmamızda ERCP ile transpapiller safra kesesi drenajı daha önceki yapılan çalışmalarla uyumlu olarak akut kolesistit için yapılmıştır. Çalışmamızda teknik başarı \%100 bulunmuş olup Hasan ve ark.'nın çalışmasındaki bulgular ile uyumludur (9). Maekawa ve ark.'nın yaptığı çalışmada ise teknik başarı oranı \% 77.5, klinik başarı oranı ise \%96.7 olarak bulunmuştur (10). Bizim çalışmamızda ise klinik başarı oranı yukarıdaki çalışmaya göre biraz düşük olmakla beraber bu hastaların ciddi komorbid durumları olup müdahale edilmediği takdirde hastaların mortal seyretmesi göz önüne alındığında klinik başarımızın yüksek olduğunu düşünüyoruz. Literatüre bakıldığında klinik başarının sağlanamadığı hastalarda kullanılan iki ana yöntem endosonografi eşliğinde safra kesesi drenajı ve perkütan kolesistostomidir. Biz de klinik başarı sağlanamayan hastalara perkütan kolesistostomi yaparak bu hastalarda klinik başarıyı sağladık.

Çalışmamızda ERCP işlemine bağlı hiçbir komplikasyon olmamıştır. Daha önce yapılan çalışmalarda sık görülen komplikasyonlardan olan stent migrasyonu bizim çalışmamızda hiç görülmemiştir. Bunun sebebi merkezimizde double pigtail veya nazosistik dren gibi kıvrık ve kaymayı zorlaştıran drenaj yöntemlerinin kullanılmış olması olabilir. Çalışmamızda işleme bağlı pankreatit hiçbir hastada görülmemiştir. Daha önceki çalışmalar ile uyumlu bulunan bu durumun sebebinin ise pankreasa tekrarlayan tel gitmesi olan hastalara uygun stentleme yapılması ve işlemlerin deneyimli endoskopistler tarafından yapılması olduğunu düşünüyoruz. Daha önce yapılan bir çalışmada bir hastada sfinkterotomi sonrası kanama görülmüşken bizim çalışmamızda hiçbir kanama olgusu saptanmadi. Bunun sebeplerinin ise endoskopistlerimizin 
deneyiminin fazla olması, sfinkterotomi sırasında pulse-cut slow akımının kullanılması ve koagülopatisi olan hastalara sfinkterotomi yapılmaksızın stentleme yapılması olduğunu düşünüyoruz.

Çalışmamızda işleme bağlı mortalite vakası görülmemiştir. Bu da işlemin güvenli olduğunu göstermektedir. Takip süresince ise toplam mortalite oranı \%26 olarak bulunmuştur. Daha önceki yapılan çalışmalarda ise total mortalite \%50 civarında bulunmuştur (7). Mortalitenin bu kadar yüksek olmasının sebebinin hastaların eşlik eden ciddi komorbit durumları olduğunu düşünüyoruz.

Çalışmamızda 19 hastadan sadece 5 hastaya sonradan kolesistektomi yapılmıştır. Bu durum ERCP ile transpapiller safra kesesi stentleme işleminin kolesistektomi ihtiyacını hastanın operasyon için uygun şartlara gelene kadar geciktirebildiğini desteklemektedir.

Sistik kanala girişim sonrası taş görülen hastalarda balon, basket, mekanik litotripsi ve sistik kanala balon dilatasyonu ile taşlar başarılı bir şekilde çıkartılmıştır. Bu işlemlere bağlı herhangi bir komplikasyon olmamıştır. Bu durum sistik kanaldaki taşların koledok taşları gibi etkin ve güvenli bir şekilde çıkartılabileceğini göstermektedir. Nitekim daha önceki yapılmış çalışmalarda özellikle ameliyat şansı olmayan ve sistik kanalda taşı olan hastalarda endoskopik tedavinin başarılı olduğu gösterilmiştir (11).

Çalışmamızın en önemli eksikliği retrospektif olması ve hasta sayısının az olmasıdır. Ancak literatür incelendiğinde, bu ve benzeri çalışmaların retrospektif yapıldığı ve hasta sayılarının ise bizim çalışmamıza benzer olduğu görülmektedir.

Sonuç olarak komorbit durumların eşlik ettiği safra kesesi veya sistik kanal ile ilişkili hastalıklarda ERCP ile transpapiller safra kesesi drenajı başarılı ve komplikasyonu az bir tedavi yöntemidir. ERCP ile transpapiller safra kesesi drenajının etkinliği ve güvenilirliği için daha büyük hasta popülasyonu ile prospektif çalışmalar yapılmasına ihtiyaç duyulmaktadir.

\section{KAYNAKLAR}

1. Ogura T, Higuchi K. A review of treatment options for bile duct stones. Expert Rev Gastroenterol Hepatol 2016;10:1271-8.

2. Williams E, Beckingham I, El Sayed G, et al. Updated guideline on the management of common bile duct stones (CBDS). Gut 2017;66:765-82

3. Paranandi B, Oppong KW. Biliary strictures: endoscopic assessment and management. Frontline Gastroenterol 2017;8:133-7.

4. ASGE Standards of Practice Committee, Chathadi KV, Chandrasekhara $\mathrm{V}$, Acosta RD, et al. The role of ERCP in benign diseases of the biliary tract. Gastrointest Endosc 2015;81:795-803.

5. Valderrama-Treviño AI, Granados-Romero JJ, Espejel-Deloiza M et al Updates in Mirizzi syndrome. Hepatobiliary Surg Nutr 2017;6:170-8.

6. Glessing BR, Attam R, Amateau SK, et al. Novel use of long, large caliber fenestrated stents for endoscopic transpapillary gallbladder stenting for therapy of symptomatic gallbladder disease. Dig Dis Sci 2015;60:381722.

7. Widmer J, Alvarez P, Sharaiha RZ, et al. Endoscopic gallbladder drainage for acute cholecystitis. Clin Endosc 2015;48:411-20.

8. Talukdar R. Complications of ERCP. Best Pract Res Clin Gastroenterol 2016;30:793-805.

9. Hasan MK, Itoi T, Varadarajulu S. Endoscopic management of acute cholecystitis. Gastrointest Endosc Clin N Am 2013;23:453-9.

10. Maekawa S1, Nomura R, Murase T, et al. Endoscopic gallbladder stenting for acute cholecystitis: a retrospective study of 46 elderlypatients aged 65 years or older. BMC Gastroenterol 2013;13:65.

11. Valderrama-Treviño AI, Granados-Romero JJ, Espejel-Deloiza M et al. Updates in Mirizzi syndrome. Hepatobiliary Surg Nutr 2017;6:170-8. 